\title{
Article \\ Usefulness of Selected Peripheral Blood Counts in Predicting Death in Patients with Severe and Critical COVID-19
}

\author{
Michał P. Pluta 1,2,*, Mateusz N. Zachura ${ }^{3} \mathbb{D}$, Katarzyna Winiarska ${ }^{3}$, Alicja Kalemba ${ }^{3}$, Cezary Kapłan ${ }^{3}$, \\ Anna J. Szczepańska ${ }^{1}$ and Łukasz J. Krzych ${ }^{1}$ (D)
}

\section{check for}

Citation: Pluta, M.P.; Zachura, M.N.; Winiarska, K.; Kalemba, A.; Kapłan, C.; Szczepańska, A.J.; Krzych, Ł.J. Usefulness of Selected Peripheral Blood Counts in Predicting Death in Patients with Severe and Critical COVID-19. J. Clin. Med. 2022, 11, 1011. https://doi.org/10.3390/ jcm11041011

Academic Editors: Natália Cruz-Martins and Célia F. Rodrigues

Received: 4 January 2022

Accepted: 13 February 2022

Published: 15 February 2022

Publisher's Note: MDPI stays neutral with regard to jurisdictional claims in published maps and institutional affiliations.

Copyright: (C) 2022 by the authors. Licensee MDPI, Basel, Switzerland. This article is an open access article distributed under the terms and conditions of the Creative Commons Attribution (CC BY) license (https:// creativecommons.org/licenses/by/ $4.0 /)$
1 Department of Anaesthesiology and Intensive Care, Faculty of Medical Sciences in Katowice, Medical University of Silesia, Medykow 14 Street, 40752 Katowice, Poland; aszczepanska@sum.edu.pl (A.J.S.); lkrzych@sum.edu.pl (Ł.J.K.)

2 Emergency Medicine Department, St. Barbara's Memorial Hospital No. 5 Trauma Center, Medyków 1 Square, 41200 Sosnowiec, Poland

3 Students' Scientific Society, Department of Anaesthesiology and Intensive Care, Faculty of Medical Sciences in Katowice, Medical University of Silesia, Medykow 14 Street, 40752 Katowice, Poland; mateusz.zachura@gmail.com (M.N.Z.); k.winiarska.97@gmail.com (K.W.); alicja.k.kalemba@gmail.com (A.K.); cezary.kaplan@gmail.com (C.K.)

* Correspondence: michal.pluta@sum.edu.pl

\begin{abstract}
Background. Immune dysregulation and hypoxemia are two important pathophysiological problems in patients with COVID-19 that affect peripheral blood count parameters. We hypothesized that assessment of the neutrophil-lymphocyte ratio (NLR) and red blood cell distribution width index (RDW-SD) could predict death in patients with severe and critical COVID-19. Methods. Seventy patients admitted to the intensive care unit (ICU) for COVID-19 acute respiratory failure were included in the study. RDW-SD and NLR on the day of ICU admission and peak values during the entire hospitalization were assessed. The primary endpoint was death before ICU discharge. Results. Patients who died had higher NLR on admission (20.3, IQR 15.3-30.2 vs. 11.0, IQR 6.8-16.9; $p=0.003$ ) and higher RDW-SD (48.1 fL; IQR 43.1-50.5 vs. $43.9 \mathrm{fL}$; IQR 40.9-47.3, $p=0.01$ ) than patients discharged from the ICU. NLR and RDW-SD values on ICU admission accurately predicted death in $76 \%(\mathrm{AUC}=0.76 ; 95 \% \mathrm{CI} 0.65-0.86 ; p=0.001$; cut-off $>14.38)$ and $72 \%$ of cases $(\mathrm{AUC}=0.72 ; 95 \% \mathrm{CI}$ $0.60-0.82 ; p=0.003$; cut-off $>44.7 \mathrm{fL}$ ), respectively. Multivariable analysis confirmed that NLR $>14.38$ on the day of ICU admission was associated with a 12-fold increased risk of death $(\log \mathrm{OR} 12.43$; 95\%CI 1.61-96.29, $p=0.02$ ), independent of other blood counts, clinical and demographic parameters. Conclusions. Neutrophil-lymphocyte ratio determined on the day of ICU admission may be a useful biomarker predicting death in patients with severe and critical COVID-19.
\end{abstract}

Keywords: COVID-19; SARS-CoV-2; intensive care unit; complete blood count; neutrophil-lymphocyte ratio; prediction

\section{Introduction}

In December 2019, the first cases of pneumonia caused by the new severe acute respiratory syndrome (SARS-CoV-2) coronavirus were diagnosed in China's Hubei province [1]. During the coronavirus disease pandemic (COVID-19) declared by the World Health Organization, 364,191,494 people were infected and 5,631,457 (1.5\%) had died by 30 January 2022 [2]. The pandemic has revealed significant financial disparities between countries, and in many of them has led to the collapse of public health systems [3]. In the face of the financial crisis and consequent impeded access to advanced diagnostic tools, it became necessary to review the utility of readily available and inexpensive laboratory parameters in prioritizing the admission of COVID-19 patients to a limited number of intensive care beds [4-6].

Patients with severe COVID-19 infection present two significant pathophysiologic problems: excessive inflammatory response (1) and hypoxemia (2). Each of these problems 
can potentially be reflected in the results of the baseline complete blood count (CBC). The inflammatory response stimulates neutrophil production and enhances lymphocyte apoptosis to a degree dependent on its severity. The neutrophil-lymphocyte ratio (NLR) may be a marker of immune dysregulation and systemic stress, providing potentially more valuable information than either parameter alone [7]. On the other hand, cellular hypoxia stimulates erythropoietin production, which accelerates the formation of red blood cells (RBCs) with increased volume (MCV), leading to an increase in red cell distribution width index (RDW). Additionally, excessive release of inflammatory cytokines inhibits the growth and shortens the survival time of RBCs, stimulating reticulocyte production, also increasing RDW [8,9].

It has been hypothesized that the assessment of these two biomarkers, NLR and RDW, may be a useful component of death risk stratification in severe and critical COVID-19 patients.

\section{Materials and Methods}

\subsection{Study Design}

This was a single-center observational study conducted in the medical ICU of a Polish University Hospital, which retrospectively evaluated the outcomes of CBC in patients admitted to the ICU between 10.2020 and $06.2021 \mathrm{r}$ with a diagnosis of severe and critical COVID-19 (i.e., second and third wave of COVID-19 in Poland). Due to the noninterventional, retrospective nature of the study, informed consent was not required from patients to participate [10]. To avoid potential influence on the results, the ICU treatment team had no knowledge of the planned data analysis.

This article was prepared in accordance with the STROBE (Strengthening The Reporting of Observational Studies in Epidemiology) reporting guidelines [11].

\subsection{Patients}

All patients hospitalized in the ICU for severe and critical COVID-19 $(n=73)$ were included in the study. COVID-19 infection was confirmed by a positive RT-PCR test. Criteria for severe COVID-19 were defined as: (1) $\mathrm{SpO}_{2}<94 \%$ in air, (2) respiratory rate $>30 / \mathrm{min}$, (3) ratio of arterial partial pressure of oxygen to inspired oxygen concentration $\left(\mathrm{PaO}_{2} / \mathrm{FiO}_{2}\right)$ $<300 \mathrm{~mm} \mathrm{Hg}$ or (4) lung lesions involving $>50 \%$ of the lung surface area [12]. Critical COVID-19 progressed to respiratory failure, septic shock, and/or multiple organ failure (MOF) [12]. ICU admission priority was determined by Society of Critical Care Medicine (SCCM) criteria adapted to local conditions, as recommended by the Polish Society of Anaesthesiology and Intensive Care (PTAiIT) [13].

Patients with a proliferative hematologic process $(n=1)$ and those requiring transfer to another center for extracorporeal blood oxygenation $(n=2)$ were excluded from the final analysis).

\subsection{Clinical Data}

Demographic and clinical data were collected, including age, gender, past medical history, priority of ICU admission according to SCCM recommendations, length of ICU hospitalization, time from admission to endotracheal intubation, degree of lung injury assessed by lung computed tomography (HRCT) analysis by an experienced radiologist, diagnosis of pulmonary embolism based on pulmonary artery angiography, methods of ventilation support (invasive and non-invasive), application of pharmacological treatment currently recommended for patients with COVID-19 by the Polish Agency for Health Technology Assessment and Tariffication, pharmacological circulatory support, extracorporeal therapies (continuous renal replacement therapy, cytokine absorbers, therapeutic plasma exchange) and ventilation in the prone position.

\subsection{Laboratory Data}

Blood for CBC was collected with a BD Vacutainer ${ }^{\mathrm{TM}}$ system (Becton Dickinson, Franklin Lakes, NJ, USA) into EDTA tubes. The material was transferred to the laboratory 
according to local protocols for handling infectious material, where it was analyzed using a Sysmex XT-1800i automated hematology analyzer (Sysmex Corporation, Kobe City, Japan) immediately upon receipt. Standard hematological parameters were determined along with an automated leukocyte smear. The frequency of CBC was at the discretion of the attending physician and was not standardized.

NLR calculation was not used in daily clinical practice. The hematology analyzer did not automatically calculate the NLR. The NLR calculation was performed retrospectively for the study. Then, based on the data from previous clinical studies and the proposal of Farkras J. [14], patients were classified into one of four groups of systemic stress severity considering only the NLR score at ICU admission: normal stress (NLR $<6$ ), mild stress (NLR 6-9), moderate stress (NLR 9-18), severe stress (NLR > 18). In addition, the maximum NLR (maxNLR) and RDW-SD (maxRDW-SD) were determined from all CBC tests performed for the patient during hospitalization in the ICU.

\subsection{Outcome}

The endpoint was the patient's death before ICU discharge.

\subsection{Statistical Analysis}

Statistical analysis was performed using procedures available in MedCalc Statistical Software version 18.2.1 (MedCalc Software bvba, Ostend, Belgium; http:/ / www.medcalc. org, accessed on 1 October 2021). Quantitative variables were presented as the median and interquartile range (IQR). Qualitative variables were presented as absolute values and percentages. The difference between quantitative variables was assessed using analysis of variance or the Kruskal-Wallis test. For qualitative variables, the chi-square test or Fisher's exact test were used when the group size was small $(\mathrm{N} \leq 30)$. Statistical relationships for dichotomous variables were assessed by odds ratio (OR) analysis. Diagnostic accuracy was assessed by ROC curves and area under curve (AUC). Finally, a logistic regression model was created in which the dependent variable was death before ICU discharge, and the independent variables were those that differed between groups at $p<0.1$ in simple analyses. Survival probability in terms of NLR on admission was subjected to Kaplan-Meier analysis and presented using log-rank tests and hazard ratio (HR) with 95\% confidence intervals (95\%CI).

The criterion for statistical significance was $p<0.05$.

\section{Results}

The final analysis included 525 CBC results in 70 patients hospitalized in the ICU. The median age of the subjects was 66 years [IQR 60-71]. The median time between CBC determinations was 2 days [IQR 1-3]. Overall, $81 \%$ of patients had died by ICU discharge $(n=57)$. Detailed demographic and clinical data are shown in Table 1.

Table 1. Selected demographic and clinical data.

\begin{tabular}{cccc}
\hline Parameter & $\begin{array}{c}\text { Survival } \\
(\boldsymbol{n}=\mathbf{1 3})\end{array}$ & $\begin{array}{c}\text { Death } \\
(\boldsymbol{n}=\mathbf{5 7})\end{array}$ & $\boldsymbol{p}$ \\
\hline Age (years) & $57(53-67)$ & $67(61-72)$ & 0.01 \\
\hline Median (IQR) & & & \\
Sex & $4(31 \%)$ & $43(75 \%)$ & 0.002 \\
male, $n(\%)$ & $9(69 \%)$ & $14(25 \%)$ & 0.002 \\
\hline
\end{tabular}


Table 1. Cont.

\begin{tabular}{|c|c|c|c|}
\hline Parameter & $\underset{(n=13)}{\text { Survival }^{1}}$ & $\begin{array}{l}\text { Death } \\
(n=57)\end{array}$ & $p$ \\
\hline \multicolumn{4}{|l|}{ Past medical history } \\
\hline Obesity, $n(\%)$ & $8(61 \%)$ & $37(65 \%)$ & 0.8 \\
\hline Hypertension, $n(\%)$ & $8(61 \%)$ & $32(56 \%)$ & 0.7 \\
\hline Diabetes, $n(\%)$ & $2(15 \%)$ & $11(19 \%)$ & 0.7 \\
\hline Chronic kidney disease, $n(\%)$ & $2(15 \%)$ & $6(11 \%)$ & 0.6 \\
\hline COPD, $n(\%)$ & $1(8 \%)$ & $5(9 \%)$ & 0.9 \\
\hline $\mathrm{CAD}, n(\%)$ & $4(31 \%)$ & $14(25 \%)$ & 0.7 \\
\hline Hypothyroidism, $n(\%)$ & $1(8 \%)$ & $3(5 \%)$ & 0.7 \\
\hline Stroke, $n(\%)$ & - & $2(4 \%)$ & - \\
\hline \multicolumn{4}{|c|}{ Duration of ICU hospitalization (days) } \\
\hline Median (IQR) & $11(8-15)$ & $8(5-13)$ & 0.3 \\
\hline \multicolumn{4}{|l|}{$\%$ lung injury ${ }^{2}$} \\
\hline Median (IQR) & $70(26-79)$ & $80(70-90)$ & 0.03 \\
\hline Pulmonary embolism, $n(\%)$ & $1(8 \%)$ & $6(10 \%)$ & 0.7 \\
\hline \multicolumn{4}{|l|}{ ICU admission priority ${ }^{3}$} \\
\hline $1, n(\%)$ & $11(85 \%)$ & $47(82 \%)$ & $<0.001$ \\
\hline $2, n(\%)$ & $2(15 \%)$ & $10(18 \%)$ & 0.02 \\
\hline \multicolumn{4}{|l|}{ Ventilation } \\
\hline HFNOT, $n(\%)$ & $8(62 \%)$ & $31(54 \%)$ & $<0.001$ \\
\hline $\mathrm{NIV}, n(\%)$ & $11(85 \%)$ & $35(61 \%)$ & $<0.001$ \\
\hline IMV, $n(\%)$ & $8(62 \%)$ & $56(98 \%)$ & $<0.001$ \\
\hline \multicolumn{4}{|c|}{ Selected arterial blood gas parameters 4} \\
\hline pH, Median (IQR) & $7.37(7.35-7.44)$ & $7.35(7.27-7.42)$ & 0.1 \\
\hline $\mathrm{pO}_{2}$, Median (IQR) & $75(63-84)$ & $67(51-88)$ & 0.5 \\
\hline $\mathrm{pCO}_{2}$, Median (IQR) & $40(32-50)$ & $39(32-50)$ & 0.9 \\
\hline$\% \mathrm{SaO}_{2}$, Median (IQR) & $94(90-96)$ & $91(86-96)$ & 0.2 \\
\hline \multicolumn{4}{|c|}{$\begin{array}{l}\text { Time from hospital admission to intubation } \\
\text { (days) }\end{array}$} \\
\hline Median (IQR) & $2.5(1.5-4)$ & $4.5(3-10)$ & 0.1 \\
\hline Prone position, $n(\%)$ & $12(92 \%)$ & $45(79 \%)$ & 0.3 \\
\hline \multicolumn{4}{|l|}{ Pharmacotherapy ${ }^{5}$} \\
\hline NMBA, $n(\%)$ & $7(54 \%)$ & $48(84 \%)$ & 0.02 \\
\hline Dexamethasone, $n(\%)$ & $13(100 \%)$ & $57(100 \%)$ & $<0.001$ \\
\hline Remdesivir, $n(\%)$ & $4(31 \%)$ & $13(23 \%)$ & 0.1 \\
\hline Tocilizumab, $n(\%)$ & $4(31 \%)$ & $15(26 \%)$ & 0.7 \\
\hline \multicolumn{4}{|c|}{ Pharmacol. support of the cardiovasc. system } \\
\hline Adrenaline, $n(\%)$ & $1(8 \%)$ & $46(81 \%)$ & $<0.001$ \\
\hline Norepinephrine, $n(\%)$ & $8(62 \%)$ & $57(100 \%)$ & $<0.001$ \\
\hline Argipressin, $n(\%)$ & $1(8 \%)$ & $26(46 \%)$ & 0.01 \\
\hline Dopamine, $n(\%)$ & - & $5(9 \%)$ & - \\
\hline Dobutamine, $n(\%)$ & $1(8 \%)$ & $11(19 \%)$ & 0.3 \\
\hline Milrinone, $n(\%)$ & - & $2(4 \%)$ & - \\
\hline \multicolumn{4}{|l|}{ Extracorporeal Therapies } \\
\hline TPE, $n(\%)$ & $2(15 \%)$ & $5(9 \%)$ & 0.5 \\
\hline CRRT, $n(\%)$ & $3(23 \%)$ & $25(44 \%)$ & 0.2 \\
\hline Cytokine adsorbers, $n(\%)$ & $1(8 \%)$ & $7(12 \%)$ & 0.6 \\
\hline
\end{tabular}

${ }^{1}$ By the discharge from the Intensive Care Unit; ${ }^{2}$ based on $\mathrm{CT}^{3}{ }^{3}$ according to the guidelines of the Society of Critical Care Medicine and the Polish Society of Anaesthesiology and Intensive Care; ${ }^{4}$ upon admission to ICU; ${ }^{5}$ including prior to admission to the Intensive Care Unit; IQR, interquartile range; COPD, chronic obstructive pulmonary disease; CAD, coronary artery disease; HFNOT, high-flow nasal oxygen therapy; NIV, non-invasive ventilation; IMV, invasive mechanical ventilation; NMBA, neuromuscular blocking agents; TPE, therapeutic plasma exchange; CRRT, continuous renal replacement therapy. 


\subsection{Peripheral Blood Leukocyte Parameters}

Patients who died before ICU discharge had a statistically significantly lower LYMPH count $(p=0.003)$ and higher NEUT count $(p=0.005)$ on the day of ICU admission. The total WBC count was not significantly different between the groups $(p=0.4)$. The values of peripheral blood morphological parameters in the study group on the day of admission to the ICU are shown in Table 2.

Table 2. Morphological parameters of peripheral blood determined on the day of admission to the Intensive Care Unit.

\begin{tabular}{|c|c|c|c|c|}
\hline Parameter & $\begin{array}{c}\text { All } \\
(n=70) \\
\text { Me (IQR) }\end{array}$ & $\begin{array}{c}\text { Survival }^{1} \\
(n=13) \\
\text { Me (IQR) }\end{array}$ & $\begin{array}{c}\text { Death } \\
(n=57) \\
\text { Me (IQR) }\end{array}$ & $p$ \\
\hline WBC $\left(\times 10^{9} \mathrm{~L}^{-1}\right)$ & $13.0(9.3-16.7)$ & $11.3(9.1-15.7)$ & $13.1(9.3-19.1)$ & 0.4 \\
\hline $\mathrm{RBC}\left(\times 10^{12} \mathrm{~L}^{-1}\right)$ & $4.1(3.6-4.7)$ & $4.1(3.7-5.0)$ & $4.1(3.5-4.7)$ & 0.3 \\
\hline $\operatorname{HGB}\left(\mathrm{g} \mathrm{dL}^{-1}\right)$ & $12.7(10.9-14.1)$ & $13.3(10.5-15.3)$ & $12.6(11.1-14.0)$ & 0.3 \\
\hline Hematocrit (\%) & $37(34-43)$ & $40(31-45)$ & $37(35-43)$ & 0.9 \\
\hline $\mathrm{MCV}(\mathrm{fL})$ & 91.1 (87-98) & 89 (85-91) & $92(88-98)$ & 0.02 \\
\hline $\mathrm{MCH}(\mathrm{pg})$ & $30(29-32)$ & $30(29-31)$ & $31(30-33)$ & 0.05 \\
\hline $\mathrm{MCHC}\left(\mathrm{g} \mathrm{dL}^{-1}\right)$ & $34(33-34)$ & $34(33-34)$ & $34(33-34)$ & 0.8 \\
\hline $\operatorname{PLT}\left(\times 10^{6} \mathrm{~L}^{-1}\right)$ & $226(176-305)$ & $254(226-370)$ & $210(168-298)$ & 0.07 \\
\hline LYMPH (\%) & $4.8(3.2-6.8)$ & $7.3(5.4-11.7)$ & $4.5(3.0-5.9)$ & 0.003 \\
\hline LYMPH $\left(\times 10^{6} \mathrm{~L}^{-1}\right)$ & $0.60(0.42-0.87)$ & $1.0(0.5-1.4)$ & $0.5(0.4-0.8)$ & 0.007 \\
\hline MONO (\%) & $3.45(2.5-4.9)$ & $4.7(3.1-5.2)$ & $3.3(2.4-4.6)$ & 0.1 \\
\hline MONO $\left(\times 10^{6} \mathrm{~L}^{-1}\right)$ & $0.43(0.27-0.63)$ & $0.5(0.4-0.7)$ & $0.4(0.2-0.6)$ & 0.2 \\
\hline NEUT $(\%)$ & $89.2(85.1-91.7)$ & $81.8(80.2-89.6)$ & $89.8(87.4-92.2)$ & 0.005 \\
\hline NEUT $\left(\times 10^{6} \mathrm{~L}^{-1}\right)$ & $11.5(7.9-15.2)$ & $9.0(7.5-12.8)$ & $11.7(8.5-17.9)$ & 0.1 \\
\hline EOS $(\%)$ & $0.0(0.0-0.1)$ & $0.0(0.0-0.2)$ & $0.0(0.0-0.0)$ & 0.3 \\
\hline $\operatorname{EOS}\left(\times 10^{6} \mathrm{~L}^{-1}\right)$ & $0.0(0.0-0.01)$ & $0.0(0.0-0.0)$ & $0.0(0.0-0.1)$ & 0.4 \\
\hline BASO (\%) & $0.2(0.1-0.2)$ & $0.2(0.1-0.3)$ & $0.1(0.1-0.2)$ & 0.2 \\
\hline BASO $\left(\times 10^{6} \mathrm{~L}^{-1}\right)$ & $0.02(0.01-0.04)$ & $0.02(0.01-0.04)$ & $0.02(0.01-0.03)$ & 0.7 \\
\hline RDW-SD (fL) & $46.9(42.9-49.8)$ & $43.9(40.9-47.3)$ & $48.1(43.1-50.5)$ & 0.01 \\
\hline PCT $(\%)$ & $0.24(0.20-0.33)$ & $0.27(0.24-0.41)$ & $0.23(0.20-0.33)$ & 0.1 \\
\hline MPV (fL) & $10.8(10.2-11.7)$ & $10.5(9.7-11.4)$ & $10.8(10.2-11.7)$ & 0.3 \\
\hline PDW (\%) & $12.8(11.1-14.4)$ & $12.1(10.8-13.6)$ & $12.9(11.3-15)$ & 0.4 \\
\hline
\end{tabular}

${ }^{1} \mathrm{By}$ the discharge from the Intensive Care Unit; Me, median; IQR, interquartile range; WBC, white blood cells; RBC, red blood cells; HGB, hemoglobin; $\mathrm{MCV}$, mean corpuscular volume; $\mathrm{MCH}$, Mean corpuscular hemoglobin; MCHC, mean corpuscular hemoglobin concentration; PLT, platelet; LYMPH, lymphocytes; MONO, monocytes; NEUT, neutrophils; EOS, eosinophils; BASO, basophils; RDW-SD; red blood cell distribution width—standard deviations; PCT, plateletcrit; MPV, mean platelet volume; PDW, platelet distribution width.

The count of LYMPH on admission to the ICU predicted death in $74 \%$ (AUC $=0.74$; $95 \%$ CI $0.62-0.84 ; p=0.007)$ at the cut-off point $\leq 0.87 \times 10^{6} \mathrm{~L}^{-1}$ with a sensitivity of $84 \%$ and specificity of $61 \%$. The NEUT value at ICU admission showed no significant accuracy in predicting the risk of death (AUC $=0.63 ; p=0.14$ ).

\subsection{Neutrophil-Lymphocyte Ratio (NLR)}

The median NLR on ICU admission was 18.1 (IQR 12.0-27.7). Patients who died had a significantly higher NLR on admission compared to patients who survived (20.3, IQR 15.3-30.2 vs. 11.0, IQR 6.8-16.9; $p=0.003$ ) (Figure 1). 


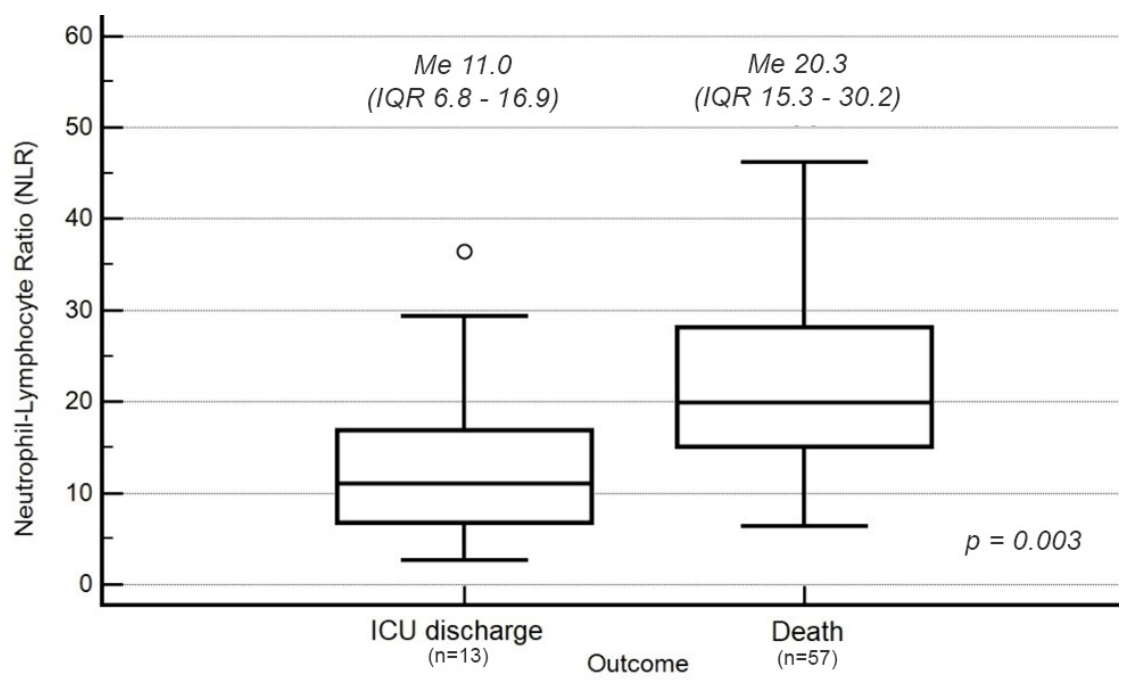

Figure 1. NLR values on admission to the ICU, and survival by the discharge from the ICU. The length of the rectangle represents the interquartile range (IQR), comprising the middle $50 \%$ of observations. The box is separated by a horizontal line that marks the median value (Me). It divides the quartile interval (Q) into two areas containing $25 \%$ of the observations. The whiskers connect the box with the largest and smallest values of the studied variable from the interval $(\mathrm{Q} 1-1.5 \times \mathrm{IQR} ; \mathrm{Q} 1)$ and (Q3; Q3 + 1.5 IQR), respectively. Dots indicate outliers.

After retrospective matching of patients to systemic stress severity group based on NLR, it was shown that mortality significantly increased with increased NLR. In the group of patients whose NLR on admission to the ICU was above 18 (severe stress group), 91\% of patients died, which accounted for $60 \%$ of all deaths in the study population (Table 3 ) (Figure 2).

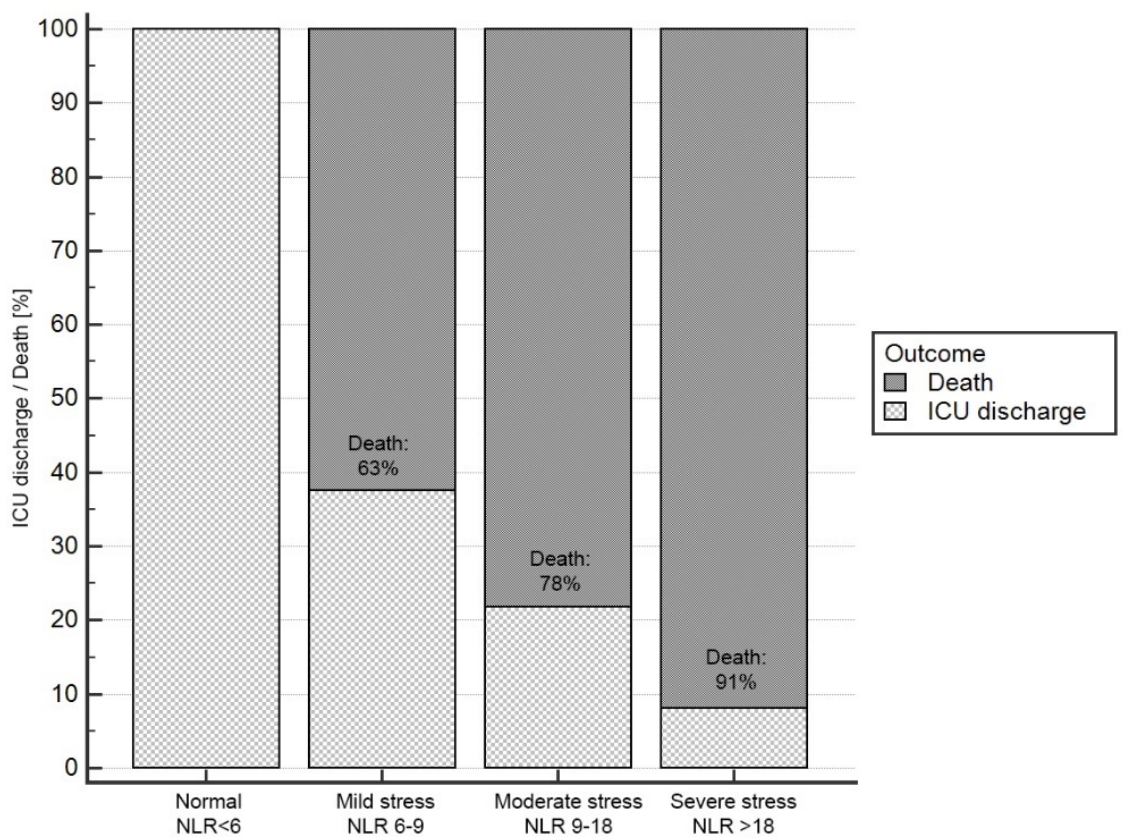

Figure 2. Final outcome of ICU treatment by systemic stress severity group (based on NLR index [14]). 
Table 3. Values of selected clinical and demographic parameters in systemic stress severity groups (based on [14]).

\begin{tabular}{|c|c|c|c|c|c|}
\hline \multirow[b]{2}{*}{ Variable } & \multicolumn{4}{|c|}{ Group } & \multirow[b]{2}{*}{$p$} \\
\hline & $\begin{array}{l}\text { Normal } \\
\text { Stress } \\
\text { NLR }<6\end{array}$ & $\begin{array}{c}\text { Mild } \\
\text { Stress } \\
\text { NLR 6-9 }\end{array}$ & $\begin{array}{l}\text { Moderate } \\
\text { Stress } \\
\text { NLR 9-18 }\end{array}$ & $\begin{array}{c}\text { Sever } \\
\text { Stress } \\
\text { NLR }>8\end{array}$ & \\
\hline$n,(\%)$ & $2(3 \%)$ & $8(11 \%)$ & $23(33 \%)$ & $37(53 \%)$ & $<0.001$ \\
\hline $\begin{array}{c}\text { Age (years) } \\
\text { Median (IQR) }\end{array}$ & $54(54-78)$ & $62(56-69)$ & $67(60-71)$ & $65(61-73)$ & 0.7 \\
\hline $\begin{array}{c}\text { Sex } \\
\text { male, } n(\%) \\
\text { female, } n(\%)\end{array}$ & $2(3 \%)$ & $\begin{array}{l}5(7 \%) \\
3(4 \%)\end{array}$ & $\begin{array}{l}16(23 \%) \\
7(10 \%)\end{array}$ & $\begin{array}{l}25(36 \%) \\
11(16 \%)\end{array}$ & $\begin{array}{c}<0.001 \\
0.03\end{array}$ \\
\hline $\begin{array}{c}\text { Duration of hospitalization in ITU (da } \\
\text { Median (IQR) }\end{array}$ & $15(4-26)$ & $12(8-14)$ & $12(6-17)$ & $8(5-9)$ & 0.2 \\
\hline $\begin{array}{l}\text { \% lung injury } \\
\text { Median (IQR) }\end{array}$ & $75(60-90)$ & $75(65-85)$ & $85(70-90)$ & $80(70-80)$ & 0.4 \\
\hline Pulmonary embolism, $n(\%)$ & - & $1(1 \%)$ & $3(4 \%)$ & $3(4 \%)$ & 0.8 \\
\hline $\begin{array}{c}\text { ICU admission priority }^{2} \\
1, n(\%) \\
2, n(\%)\end{array}$ & $\begin{array}{c}2(3 \%) \\
-\end{array}$ & $\begin{array}{l}5(7 \%) \\
3(4 \%)\end{array}$ & $\begin{array}{l}21(30 \%) \\
2(3 \%)\end{array}$ & $\begin{array}{c}30(43 \%) \\
7(10 \%)\end{array}$ & $\begin{array}{c}<0.001 \\
0.2\end{array}$ \\
\hline $\begin{array}{c}\text { Ventilation } \\
\text { HFNOT, } n(\%) \\
\text { NIV, } n(\%) \\
\text { IMV, } n(\%)\end{array}$ & $\begin{array}{l}2(3 \%) \\
2(3 \%) \\
1(1 \%)\end{array}$ & $\begin{array}{l}5(7 \%) \\
5(7 \%) \\
6(9 \%)\end{array}$ & $\begin{array}{l}13(19 \%) \\
15(21 \%) \\
21(30 \%)\end{array}$ & $\begin{array}{l}19(27 \%) \\
24(34 \%) \\
36(51 \%)\end{array}$ & $\begin{array}{c}0.6 \\
0.8 \\
0.03\end{array}$ \\
\hline Prone position, $n(\%)$ & $2(3 \%)$ & $8(11 \%)$ & $18(26 \%)$ & $29(41 \%)$ & 0.4 \\
\hline $\begin{array}{l}\text { Pharmacol. support of the cardiovas } \\
\text { system } \\
\text { Adrenaline, } n(\%) \\
\text { Norepinephrine, } n(\%) \\
\text { Argipressin, } n(\%) \\
\text { Dopamine, } n(\%) \\
\text { Dobutamine, } n(\%) \\
\text { Milrinone, } n(\%)\end{array}$ & $\begin{array}{c}- \\
1(1 \%) \\
- \\
- \\
- \\
-\end{array}$ & $\begin{array}{c}5(7 \%) \\
6(9 \%) \\
2(3 \%) \\
- \\
2(3 \%) \\
-\end{array}$ & $\begin{array}{c}15(21 \%) \\
21(30 \%) \\
11(16 \%) \\
2(3 \%) \\
2(3 \%) \\
-\end{array}$ & $\begin{array}{c}27(39 \%) \\
37(53 \%) \\
14(20 \%) \\
3(4 \%) \\
8(11 \%) \\
2(3 \%)\end{array}$ & $\begin{array}{c}0.2 \\
0.006 \\
0.4 \\
0.8 \\
0.5 \\
0.6\end{array}$ \\
\hline $\begin{array}{c}\text { Extracorporeal therapies } \\
\text { TPE, } n(\%) \\
\text { CRRT, } n(\%) \\
\text { Cytokine adsorbers, } n(\%)\end{array}$ & $\begin{array}{l}- \\
-\end{array}$ & $\begin{array}{c}1(1 \%) \\
4 \\
3(4 \%)\end{array}$ & $\begin{array}{c}3(4 \%) \\
7(10 \%) \\
1(1 \%)\end{array}$ & $\begin{array}{c}3(4 \%) \\
17(24 \%) \\
4(6 \%)\end{array}$ & $\begin{array}{c}0.9 \\
0.4 \\
0.08\end{array}$ \\
\hline Death before discharge from ICU & - & $5(7 \%)$ & $18(26 \%)$ & $34(49 \%)$ & 0.003 \\
\hline
\end{tabular}

${ }^{1}$ Based on CT; ${ }^{2}$ according to the guidelines of the Society of Critical Care Medicine and the Polish Society of Anaesthesiology and Intensive Care; IQR, interquartile range; HFNOT, high-flow nasal oxygen therapy; NIV, noninvasive ventilation; IMV, invasive mechanical ventilation; TPE, therapeutic plasma exchange; CRRT, continuous renal replacement therapy.

Patients in the higher systemic stress group (according to the NLR score) had a threefold higher risk of death than patients classified in the lower group $(\mathrm{OR}=3.32 ; 95 \% \mathrm{CI}$ $1.50-7.36 ; p=0.003)$.

NLR value on ICU admission predicted death with 76\% accuracy (AUC $=0.76 ; 95 \% \mathrm{CI}$ $0.65-0.86 ; p=0.001$ ) at NLR cut-off point $>14.38$ with $77 \%$ sensitivity and $69 \%$ specificity. NLR value above the indicated cut-off point indicated a seven-fold increased risk of death $(\mathrm{OR}=7.61 ; 95 \% \mathrm{CI} 2.01-28.81 ; p=0.002)$.

When analyzing NLR values throughout the ICU stay, patients who ultimately died presented significantly higher maximum NLR (maxNLR) values during hospitalization (34.98, IQR 22.51-58.54 vs. 18.13, IQR 7.45-29.79; $p=0.001)$. A maxNLR value $>31.51$ 
was associated with death in 79\% of cases (AUC $=0.79 ; 95 \%$ CI $0.68-0.88 ; p<0.001)$ with a sensitivity of $58 \%$ and specificity of $92 \%$.

A comparison of ROC curves for selected leukocyte parameters, determined on ICU admission, is shown in Figure 3.

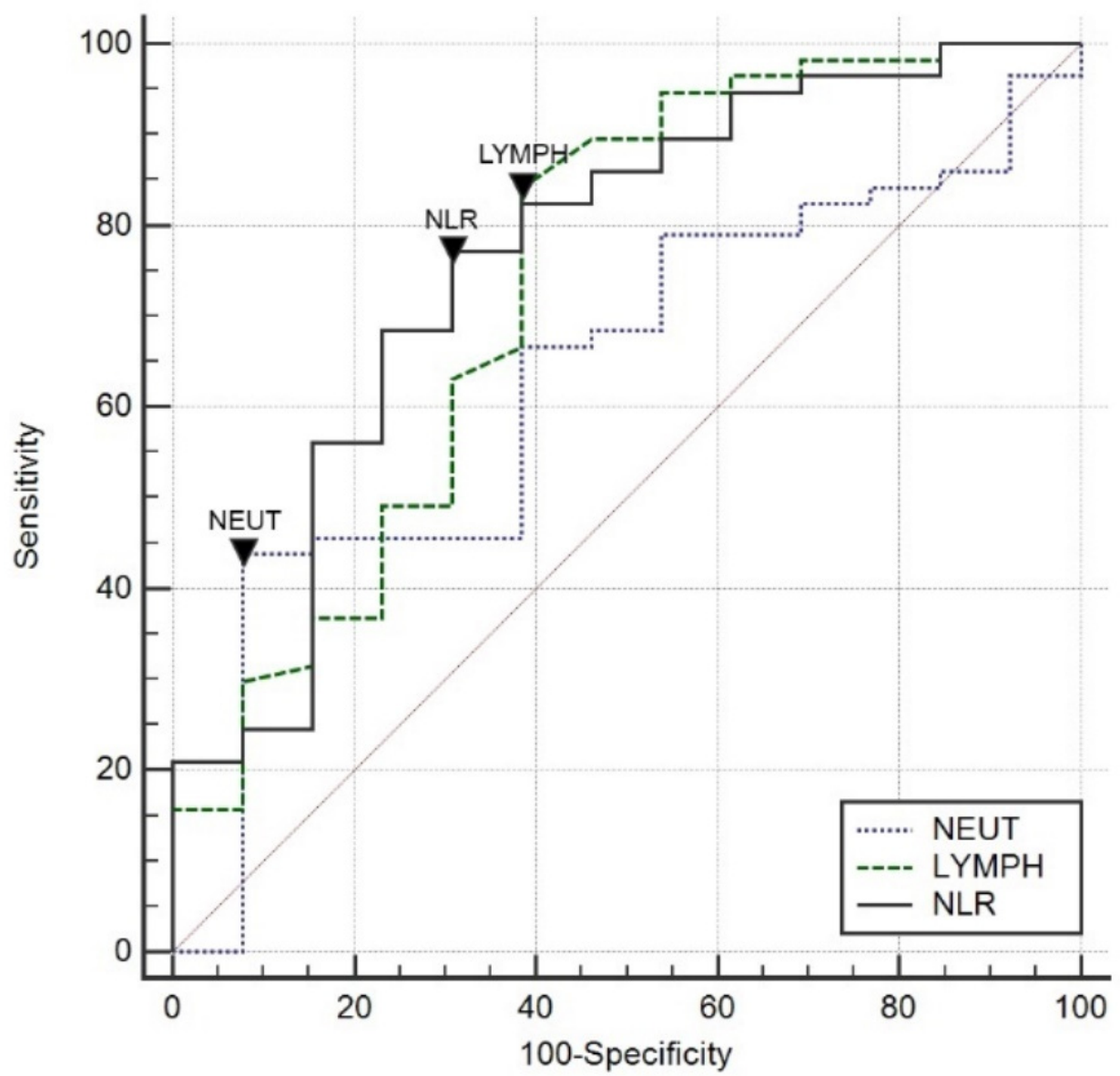

Figure 3. Comparison of ROC curves for selected leukocyte parameters measured on admission to the ICU.

\subsection{Red Cell Distribution Width (RDW)}

In terms of red blood cell parameters, patients who died had statistically significantly higher RDW-SD values on ICU admission compared to patients who survived prior to ICU discharge (48.1 fL; IQR 43.1-50.5 vs. 43.9 fL; IQR 40.9-47.3, $p=0.01$ ) (normal laboratory range in the study center: 38.90-50 fL) (Figure 4)

An RDW-SD value on ICU admission above $44.7 \mathrm{fL}$ accurately predicted death in $72 \%$ of cases (AUC $=0.72 ; 95 \%$ CI $0.60-0.82 ; p=0.003$ ) with a sensitivity of $70 \%$ and specificity of $69 \%$. An RDW-SD score $>44.7 \mathrm{fL}$ on ICU admission was associated with a greater than five-fold increased risk of death (OR $=5.29 ; 95 \%$ CI 1.43-19.56; $p=0.009)$.

Similar to NLR, maximum RDW-SD (maxRDW-SD) values during ICU hospitalization were significantly higher in patients who had died by ICU discharge. A maxRDW-SD value $>46.8 \mathrm{fL}$ predicted death in $76 \%$ of cases $(\mathrm{AUC}=0.76 ; 95 \% \mathrm{CI} 0.65-0.86 ; p=0.006$ ) with a sensitivity of $91 \%$ and specificity of $62 \%$. 


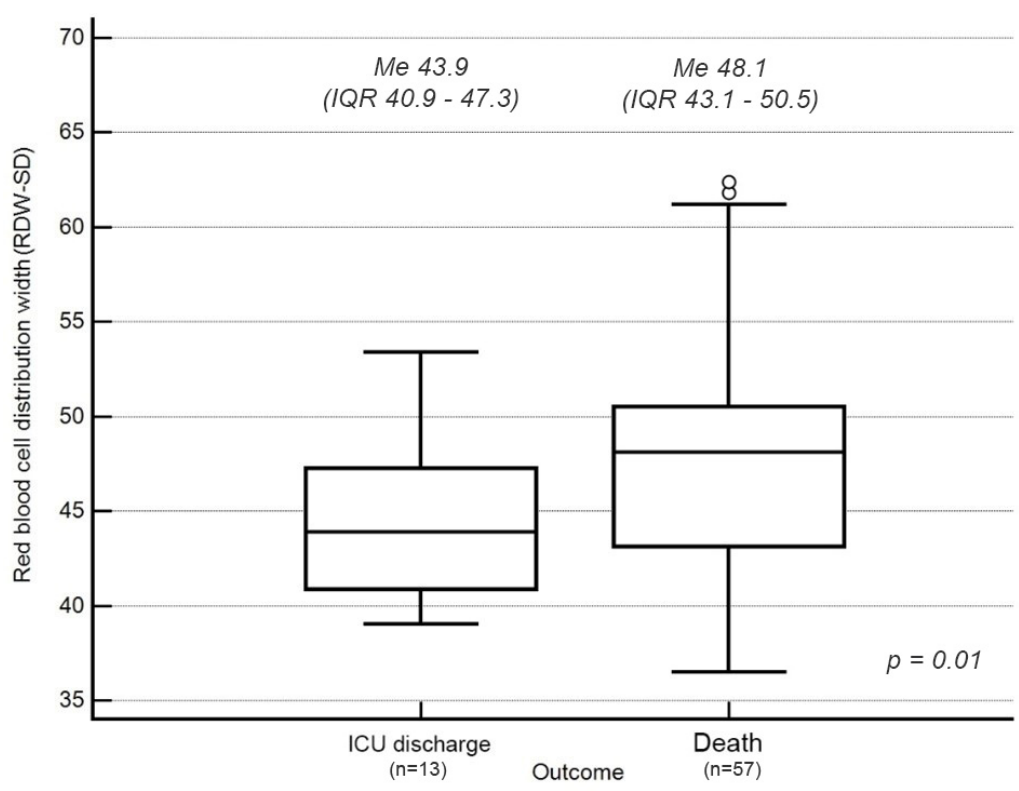

Figure 4. RDW-SD values at ICU admission and survival to ICU discharge. The length of the rectangle represents the interquartile range (IQR), comprising the middle $50 \%$ of observations. The box is separated by a horizontal line that marks the median value (Me). It divides the quartile interval (Q) into two areas containing $25 \%$ of the observations. The whiskers connect the box with the largest and smallest values of the studied variable from the interval (Q1 - 1.5 × IQR; Q1) and (Q3; Q3 + 1.5 IQR), respectively. Dots indicate outliers.

\subsection{Logistic Regression Model}

A logistic regression model confirmed that NLR $>14.38$ on ICU admission, regardless of other parameters (i.e., age, sex, degree of lung injury on HRCT, LYMPH, NEUT, and RDW-SD), was associated with a greater than 12-fold increased risk of death $(\log \mathrm{OR} 12.43$; 95\%CI 1.61-96.29, $p=0.02$ przy AUC $=0.90 ; 95 \%$ CI 0.79-0.97; $p=0.049$ ).

\subsection{Survival Analysis}

Kaplan-Meier analysis showed that patients with an NLR $>14.38$ on ICU admission had a significantly higher risk of death compared to patients with a lower NLR (log-rank test; $p=0.003$; HR 2.29, 95\%CI 1.35-3.88) (Figure 5).

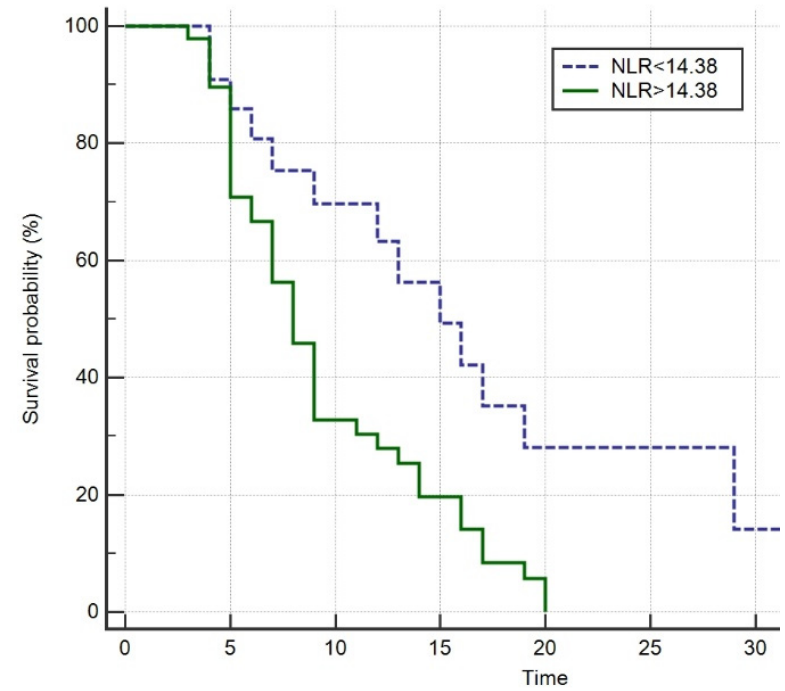

Figure 5. Survival probability in terms of NLR on admission. 


\section{Discussion}

This single-center observational study demonstrated that the NLR value on ICU admission was a useful predictor of death in severe and critical COVID-19 patients, independent of RDW-SD and other clinical and demographic parameters. The study was retrospective, clinicians were not informed of the planned data analysis, and the NLR score was not routinely provided by the hospital laboratory. To our knowledge, no clinicians calculated the NLR for clinical decision making.

Previous studies have shown a leukocyte pattern characteristic of COVID-19, i.e., higher NEUT and lower LYMPH [15]. Since inflammatory cytokines stimulate the maturation of T cells that destroy SARS-CoV-2-infected cells, lymphocytosis correlates with an increased risk of death. The percentage of CD8+ T cells is significantly lower in severe and critical COVID-19 patients, but unlike NEUT and LYMPH counts, lymphocyte subpopulation analysis is not currently routine clinical practice [16]. In our study, when considering the classification of systemic stress proposed by Farkras J. [14], patients in the NLR $<6$ (normal stress) group survived before ICU discharge, although the degree of lung involvement on HRCT was not significantly different compared to the severe systemic stress group (NLR > 18), in which mortality was 91\%. Multivariate analysis also identified NLR as a predictor of death independent of the degree of lung injury. These observations support the involvement of cytokine storms in the development of MOF in the course of COVID-19. However, it is worth noting that in our study, the degree of lung injury was subjectively assessed by the radiologist. When Liu F. et al. used artificial intelligence algorithms to evaluate HRCT images, they were more useful in risk stratification than any laboratory parameters, but such systems are not routinely used [17]. The NLR cut-off point for assessing the risk of disease progression or death varied between studies. Yang A. et al. showed that age $<49.5$ years and NLR $<3.3$ predicted hospital discharge after approximately 13.5 days of hospitalization (AUC 0.84; $p<0.05$ ) [18]. Shang W. et al. identified NLR $>4.28$ as predictive of severe COVID-19 (AUC $=0.74 ; p<0.001$ ) [19]. In the study by Yan X. et al. [20], NLR > 11.75 value predicted in-hospital death from any cause with very good accuracy (AUC $=0.94 ; p<0.01$ ). A recent meta-analysis by Ulloque-Badaracco JR et al., which included 61 studies ( $n=15,522$ patients), showed that an increase of one NLR unit was associated with a higher risk of disease progression (OR 6.22; 95\%CI 4.93-7.84; $p<0.001$ ) and a higher risk of in-hospital death from any cause (OR 12.6; 95\%CI 6.88-23.06; $p<0.001$ ) [21]. In our study, the optimal cut-off point on the ROC curve for predicting death corresponded to NLR $>14.38$, and the AUC for NLR was higher than that for NEUT and LYMPH separately. Given the lack of cost associated with obtaining NLR values, the NLR parameter should be routinely provided to clinicians by the laboratory with CBC results. The usefulness of NLR has also been demonstrated in many other clinical situations [22,23].

In our study group, we noted an alarmingly high mortality rate (81\%). However, by taking NLR as an indicator of disease severity, we included sicker patients in our study than other investigators (median NLR at admission 18.1; IQR 12.0-27.7). For example, in the cited meta-analysis by Ulloque-Badaracco JR et al., only 3 of 61 studies had a median NLR higher than 18.1, and the mortality reported in one of them was even higher than in our center (87.5\%) [18]. The other authors did not disclose the number of deaths.

Our observations have important implications for daily clinical practice. NLR assessment can support the identification of patients at risk of COVID-19 progression to MOF and death, and therefore indicate the need for early eligibility for centers with extracorporeal support methods. On the other hand, in a situation of limited access to mechanical ventilation, the effective identification of patients who will not benefit from the implementation of methods and techniques reserved for the ICU will allow the targeting of human and equipment resources to patients potentially promising for recovery. This type of triage is a key component of incident management where the number of casualties exceeds available forces and resources, familiar from disaster and battlefield medicine [24]. 


\section{Limitations}

Our study has several limitations. First, it was a single-center observation, so the results cannot be uncritically extrapolated to other populations. Second, the NLR value may be affected by the use of exogenous glucocorticosteroids [14,25]. Although the management of dexamethasone use in our ICU was consistent with the AOTM recommendations, we cannot guarantee that the recommendations were followed prior to ICU admission [26]. Third, we did not analyze other potential causes of lymphopenia and lymphocytosis or neutropenia and neutrocytosis, but a priori excluded patients suspected of having a proliferative hematologic process from our analysis. Fourth, although many publications have referred to the usefulness of NLR in COVID-19, few of the studies involved such an extremely severe group of patients.

\section{Conclusions}

The neutrophil-lymphocyte ratio determined on the day of intensive care unit admission may be a useful biomarker for predicting death in patients with severe and critical COVID-19, even after accounting for other relevant medical variables.

Author Contributions: Conceptualization, M.P.P. and Ł.J.K.; methodology, M.P.P. and Ł.J.K.; collecting data, M.P.P., M.N.Z., K.W., A.K., C.K. and A.J.S.; formal analysis, M.P.P. and Ł.J.K.; investigation, M.P.P., M.N.Z., K.W., A.K., C.K., A.J.S. and Ł.J.K.; writing-original draft preparation, M.P.P., A.J.S. and Ł.J.K.; writing—review and editing, M.P.P., A.J.S. and Ł.J.K.; visualization, M.P.P., A.J.S. and Ł.J.K.; supervision, Ł.J.K. All authors have read and agreed to the published version of the manuscript.

Funding: This research received no external funding.

Institutional Review Board Statement: Due to the non-interventional, retrospective type of the study, patients' consent to participate in the study was not obtained.

Informed Consent Statement: Due to the observational type of the study, the consent of the participants to participate in the study was not required.

Data Availability Statement: Data are available from the authors of the study.

Conflicts of Interest: The authors declare no conflict of interest.

\section{References}

1. Chan, J.F.W.; Kok, K.H.; Zhu, Z.; Chu, H.; To, K.K.W.; Yuan, S.; Yuen, K.Y. Genomic characterization of the 2019 novel humanpathogenic coronavirus isolated from a patient with atypical pneumonia after visiting Wuhan. Emerg. Microbes Infect. 2020, 9 , 221-236. [CrossRef] [PubMed]

2. World Health Organization. Available online: http:/ / www.covid19.who.int (accessed on 30 January 2022).

3. Mena, G.; Martinez, P.P.; Mahmud, A.S.; Marquet, P.A.; Buckee, C.O.; Santillana, M. Socioeconomic status determines COVID-19 incidence and related mortality in Santiago, Chile. Science 2021, 372, eabg5298. [CrossRef]

4. Keddie, S.; Ziff, O.; Chou, M.K.; Taylor, R.L.; Heslegrave, A.; Garr, E.; Lakdawala, N.; Church, A.; Ludwig, D.; Manson, J.; et al. Laboratory biomarkers associated with COVID-19 severity and management. Clin. Immunol. 2020, 221, 108614. [CrossRef] [PubMed]

5. Samprathi, M.; Jayashree, M. Biomarkers in COVID-19, An Up-To-Date Review. Front. Pediatr. 2021, 8, 607647. [CrossRef] [PubMed]

6. Zeng, Z.Y.; Feng, S.D.; Chen, G.P.; Wu, J.N. Predictive value of the neutrophil to lymphocyte ratio for disease deterioration and serious adverse outcomes in patients with COVID-19, a prospective cohort study. BMC Infect. Dis. 2021, 21, 80. [CrossRef] [PubMed]

7. Zhu, Z.; Cai, T.; Fan, L.; Lou, K.; Hua, X.; Huang, Z. Clinical value of immune-inflammatory parameters to assess the severity of coronavirus disease 2019. Int. J. Infect. Dis. 2020, 95, 332-339. [CrossRef] [PubMed]

8. Zhang, W.; Wang, Y.; Wang, J.; Wang, S. Association between red blood cell distribution width and long-term mortality in acute respiratory failure patients. Sci. Rep. 2020, 10, 21185. [CrossRef]

9. Pluta, M.; Klocek, T.; Krzych, Ł.J. Diagnostic accuracy of red blood cell distribution width in predicting in-hospital mortality in patients undergoing high-risk gastrointestinal surgery. Anaesthesiol. Intensive Ther. 2018, 50, 277-282. [CrossRef]

10. Ustawa z Dnia 5 Grudnia 1996, r. o Zawodzie Lekarza; Rozdz.4 (Tekst Jedn. Dz.U. 1997 nr 28 Poz. 152). Available online: http:/ /isap.sejm.gov.pl/ (accessed on 15 December 2021). (In Polish) 
11. Von Elm, E.; Altman, D.G.; Egger, M.; Pocock, S.J.; Gøtzsche, P.C.; Vandenbroucke, J.P. STROBE Initiative. The Strengthening the Reporting of Observational Studies in Epidemiology (STROBE) statement: Guidelines for reporting observational studies. J. Clin. Epidemiol. 2008, 61, 344-349. [CrossRef]

12. COVID-19 Treatment Guidelines Panel, National Institutes of Health. Coronavirus Disease 2019 (COVID-19) Treatment Guidelines. Available online: https:/ / www.covid19treatmentguidelines.nih.gov/ (accessed on 20 November 2021).

13. Nates, J.L.; Nunnally, M.; Kleinpell, R.; Blosser, S.; Goldner, J.; Birriel, B. ICU Admission, Discharge, and Triage Guidelines: A Framework to Enhance Clinical Operations, Development of Institutional Policies, and Further Research. Crit. Care Med. 2016, 44, 1553-1602. [CrossRef]

14. Farkas, J. PulmCrit: Neutrophil-Lymphocyte Ratio (NLR): Free Upgrade to Your WBC. Available online: https: / / emcrit.org/ pulmcrit/nlr/ (accessed on 1 October 2020)

15. Liu, Y.; Du, X.; Chen, J.; Jin, Y.; Peng, L.; Wang, H.H.X. Neutrophil-to-lymphocyte ratio as an independent risk factor for mortality in hospitalized patients with COVID-19. J. Infect. 2020, 81, e6-e12. [CrossRef] [PubMed]

16. Qin, C.; Zhou, L.; Hu, Z.; Zhang, S.; Yang, S.; Tao, Y. Dysregulation of immune response in patients with COVID-19 in Wuhan, China. Clin. Infect. Dis. 2020, 71, 762-768. [CrossRef] [PubMed]

17. Liu, F.; Zhang, Q.; Huang, C.; Shi, C.; Wang, L.; Shi, N. CT quantification of pneumonia lesions in early days predicts progression to severe illness in a cohort of COVID-19 patients. Theranostics 2020, 10, 5613-5622. [CrossRef] [PubMed]

18. Yang, A.-P.; Liu, J.-P.; Tao, W.-Q.; Li, H.-M. The diagnostic and predictive role of NLR, d-NLR and PLR in COVID-19 patients. Int. Immunopharmacol. 2020, 84, 106504. [CrossRef]

19. Shang, W.; Dong, J.; Ren, Y.; Tian, M.; Li, W.; Hu, J. The value of clinical parameters in predicting the severity of COVID-19. J. Med. Virol. 2020, 92, 2188-2192. [CrossRef]

20. Yan, X.; Li, F.; Wang, X.; Yan, J.; Zhu, F.; Tang, S. Neutrophil to lymphocyte ratio as prognostic and predictive factor in patients with coronavirus disease 2019, A retrospective cross-sectional study. J. Med. Virol. 2020, 92, 2573-2581. [CrossRef]

21. Ulloque-Badaracco, J.R.; Ivan Salas-Tello, W.; Al-kassab-Córdova, A.; Alarcón-Braga, E.A.; Benites-Zapata, V.A.; Maguiña, J.L.; Hernandez, A.V. Prognostic value of neutrophil-to-lymphocyte ratio in COVID-19 patients: A systematic review and meta-analysis. Int. J. Clin. Pract. 2021, 75, e14596. [CrossRef]

22. Kaushik, R.; Gupta, M.; Sharma, M.; Jash, D.; Jain, N.; Sinha, N. Diagnostic and Prognostic Role of Neutrophil-to-Lymphocyte Ratio in Early and Late Phase of Sepsis. Indian J. Crit. Care Med. 2018, 22, 660-663. [CrossRef]

23. Huang, Z.; Fu, Z.; Huang, W.; Huang, K. Prognostic value of neutrophil-to-lymphocyte ratio in sepsis: A meta-analysis. Am. J. Emerg. Med. 2020, 38, 641-647. [CrossRef]

24. Falzone, E.; Pasquier, P.; Hoffmann, C.; Barbier, O.; Boutonnet, M.; Salvadori, A. Triage in military settings. Anaesth. Crit. Care Pain Med. 2017, 36, 43-51. [CrossRef]

25. Karakonstantis, S.; Kalemaki, D.; Tzagkarakis, E.; Lydakis, C. Pitfalls in studies of eosinopenia and neutrophil-to-lymphocyte count ratio. Infect. Dis. 2018, 50, 163-174. [CrossRef] [PubMed]

26. Polish Diagnostic, Therapeutic and Organisational Recommendations for the Care of Individuals Infected with SARS-CoV-2 or Exposed to a SARS-CoV-2 Infection. Available online: http:/ / aotm.gov.pl (accessed on 14 December 2021). 